Article

\title{
Fatigue Life Prediction of High Modulus Asphalt Concrete Based on the Local Stress-Strain Method
}

\author{
Mulian Zheng ${ }^{1, *}$, Peng $\mathrm{Li}^{1}{ }^{1, *}$, Jiangang Yang ${ }^{2}$, Hongyin $\mathrm{Li}^{3}$, Yangyang Qiu ${ }^{4}$ and \\ Zhengliang Zhang ${ }^{5}$ \\ 1 Key Laboratory for Special Area Highway Engineering of Ministry of Education, Chang'an University, \\ South Erhuan Middle Section, Xi'an 710064, Shaanxi, China \\ 2 Civil Engineering Materials Laboratory, East China Jiaotong University, Shuang Gang East Street, \\ Nanchang 330000, Jiangxi, China; mjgchd@163.com \\ 3 Shandong Highway Administration Bureau, Shungeng Road of Jinan City, Jinan 250000, Shandong, China; \\ chdmaqiang@163.com \\ 4 Jinhua Traffic Planning and Design Institute, Songlian Road of Jin Dong District, \\ Jinhua 321015, Zhejiang, China; qiu_yangyang@126.com \\ 5 Anhui Highway Administration Center, Da Bie Shan Road of Hefei City, Hefei 230088, Anhui, China; \\ xuhaileilie@163.com \\ * Correspondence: zhengml@chd.edu.cn (M.Z.); lp042820321@126.com (P.L.); Tel.: +86-29-8233-4846 (M.Z.)
}

Academic Editors: Zhanping You, Qingli (Barbara) Dai and Feipeng Xiao

Received: 23 January 2017; Accepted: 15 March 2017; Published: 20 March 2017

\begin{abstract}
Previously published studies have proposed fatigue life prediction models for dense graded asphalt pavement based on flexural fatigue test. This study focused on the fatigue life prediction of High Modulus Asphalt Concrete (HMAC) pavement using the local strain-stress method and direct tension fatigue test. First, the direct tension fatigue test at various strain levels was conducted on HMAC prism samples cut from plate specimens. Afterwards, their true stress-strain loop curves were obtained and modified to develop the strain-fatigue life equation. Then the nominal strain of HMAC course determined using finite element method was converted into local strain using the Neuber method. Finally, based on the established fatigue equation and converted local strain, a method to predict the pavement fatigue crack initiation life was proposed and the fatigue life of a typical HMAC overlay pavement which runs a risk of bottom-up cracking was predicted and validated. Results show that the proposed method was able to produce satisfactory crack initiation life.
\end{abstract}

Keywords: pavement engineering; high modulus asphalt concrete; local stress-strain; modified Neuber equation; fatigue life

\section{Introduction}

Fatigue damage refers to the accumulation of damage in asphalt concrete, causing cracks and fracture extensions, and ultimately resulting in loading failure. Fatigue failure includes the formation of the crack nucleation stage (fatigue), crack extension (stability) of crack growth, and fracture failure (unstable crack propagation). Because fracture failure happens rapidly, the fatigue life of pavement generally includes crack formation and propagation. The term "stage of fatigue crack initiation" usually refers to the fatigue crack nucleation and propagation, which require examination during engineering processes. In road engineering the period from crack nucleation to the crack reaching a length of $5 \mathrm{~mm}$ is treated as the life of the initiation of the fatigue crack.

There are different approaches to quantify the fatigue crack process in asphalt concrete mixtures. Among the different approaches, practitioners primarily use the strain approach, which was first introduced by Monismith, and the energy approaches because these approaches are simple and 
consist of experimentally oriented procedures [1-3]. The most common fatigue model adopted by the Mechanistic Empirical Pavement Design Guide (MEPDG) is a strain approach that considers the material's properties using the value of dynamic modulus forms [4]. Al-Qadi described the dissipated energy changes during loading and proposed four parameters to define fatigue performance for $13 \mathrm{~mm}$ dense-graded Hot Mix Asphalt (HMA) using bending beams at various strain amplitudes [5]. Molayem used continuum damage theory to characterize the fatigue properties of asphalt binders and their effect on fatigue resistance. This proposed model can be used as an alternative to time-consuming beam fatigue tests [6].

Metcalf evaluated the Strategic Highway Research Program (SHRP) fatigue crack initiation life prediction model with crack measurements in laboratory slab fatigue tests. The study showed that the SHRP crack initiation life model significantly underestimates the fatigue crack initiation life for slabs [7].

Kim developed a system for predicting the fatigue life of asphalt mixtures. This work indicates that the fatigue life of a mixture subjected to sinusoidal strain loading can be determined through the model's damage principles using IDT (indirect tensile test) test results [8]. Ali Khodaii employed a large scale experimental setup to examine the influence of the most important parameters on delaying reflection cracking in geogrid reinforced overlay in bending mode. Regression equations were developed to estimate fracture parameters which can be used to predict the crack growth rate in order to design asphalt overlay that is protected from reflective cracking [9].

One of the major achievements of the SHRP asphalt mix research projects is the development of a fatigue life prediction model based on the results of intensive bending beam fatigue tests. Several researchers have conducted fatigue testing on asphalt concrete in the laboratory to investigate fatigue life through bending beam fatigue tests [10-16]. Although this model covers a wide range of asphalt mix related fatigue variables, it has to apply a shift factor to deal with the stress concentration of cracks in High Modulus Asphalt Concrete (HMAC), including the state of stress. It would be helpful to determine how real stress state contributes to fatigue life, because local stress and direct tensile tests more realistically simulate the multiaxial state of stress and cracking in pavements than bending beam tests.

A basic principle of the local stress-strain method is that the nominal stress and strain of a structure under various loadings are firstly converted into local stress and strain at the most unfavorable points (i.e., the stress concentration points) based on the stress-strain loop curve obtained from the fatigue test. Combined with the established strain-fatigue life curve, these local stresses and strains are then corrected and used to estimate fatigue life of the structure.

Local stress-strain fatigue analysis focuses on determining local stress and strain. In the local stress concentration area, there is a complex nonlinear relationship between the stress, strain, and load. Methods for determining the local strain and stress include the test method, the elastic-plastic finite element method, and the approximate calculation method.

In this paper, we conduct direct tensile fatigue tests and cyclic stress-strain tests at different strain levels to determine the fatigue properties of HMAC, and propose a method to predict the fatigue crack initiation life of HMAC. This method is based on a modified Neuber equation and the local stress-strain method.

\section{Process for Fatigue Life Estimation Based on the Local Stress-Strain Method}

The fatigue life prediction method consists of three aspects: fatigue performance of the material, transformation from nominal stress and strain into local stress and strain, and fatigue cumulative damage theory. A modified Neuber equation was used to transform nominal stress-strain to local stress-strain. The Miner theory and Manson-Coffin equation have been widely used to characterize cumulative fatigue damage. Therefore, the cyclic stress-strain curve and strain-life curve can be combined as the local stress-strain method to estimate the fatigue crack life. 
The raw data needed for calculation includes the elastic modulus, the steady cyclic stress-strain curve, the strain-life curve, the theoretical stress concentration factor, and load history.

Steps for fatigue life estimation, based on the local stress-strain method, are shown in Figure 1.

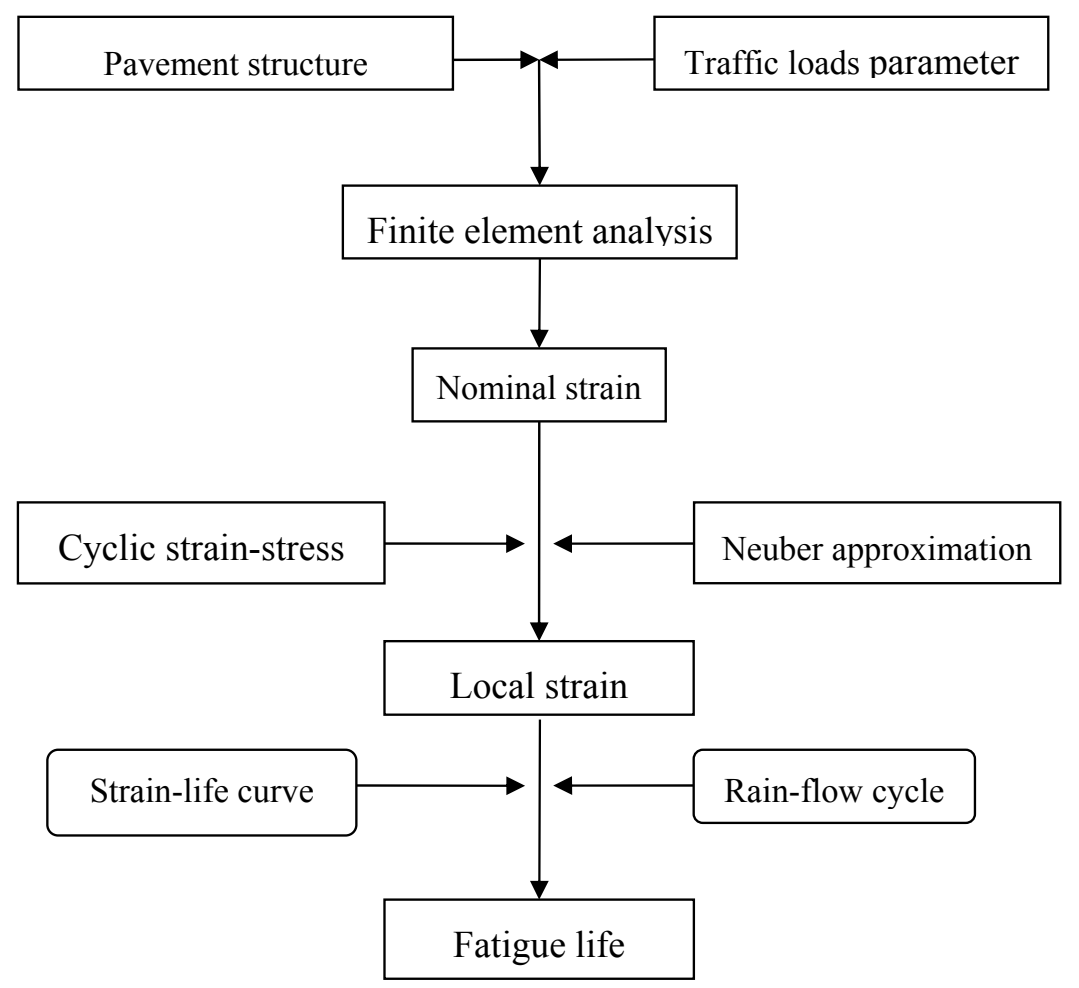

Figure 1. Process for fatigue life estimation based on local stress-strain method.

\section{Direct Tensile Test of HMAC}

\subsection{Materials}

90\# asphalt was used to compound the high-modulus asphalt in the research. Details of the materials are listed in Table 1.

Table 1. Test results of 90\# asphalt.

\begin{tabular}{ccc}
\hline Items & Unit & Value \\
\hline $25^{\circ} \mathrm{C}$ Penetration & $0.1 \mathrm{~mm}$ & 83 \\
Penetration Index & $\ldots$ & -0.84 \\
Ductility $\left(10^{\circ} \mathrm{C}\right)$ & $\mathrm{cm}$ & 42 \\
Ductility $\left(15^{\circ} \mathrm{C}\right)$ & $\mathrm{cm}$ & $>150$ \\
Softening Point & ${ }^{\circ} \mathrm{C}$ & 49.3 \\
Flashing Point & ${ }^{\circ} \mathrm{C}$ & 282 \\
Paraffin Content (distillation) & $\%$ & 0.91 \\
Solubility $\left(\mathrm{C}_{2} \mathrm{HCl}_{3}\right)$ & $\%$ & 99.8 \\
Density $\left(15^{\circ} \mathrm{C}\right)$ & $\mathrm{g} / \mathrm{cm}^{3}$ & 0.982 \\
Quality Change & $\%$ & -0.005 \\
Penetration Ratio & $\%$ & 68.5 \\
TFOT $\left(163{ }^{\circ} \mathrm{C}, 5\right.$ h) $\quad$ Ductility $\left(15^{\circ} \mathrm{C}\right)$ & $\mathrm{cm}$ & 38.6 \\
Ductility $\left(10^{\circ} \mathrm{C}\right)$ & $\mathrm{cm}$ & 9.6 \\
\hline
\end{tabular}

PR PLASTS was chosen as the HMAC-20 additive with a dosage of $0.6 \%$. The mineral aggregate gradation of the HMAC-20 is shown in Figure 2. 


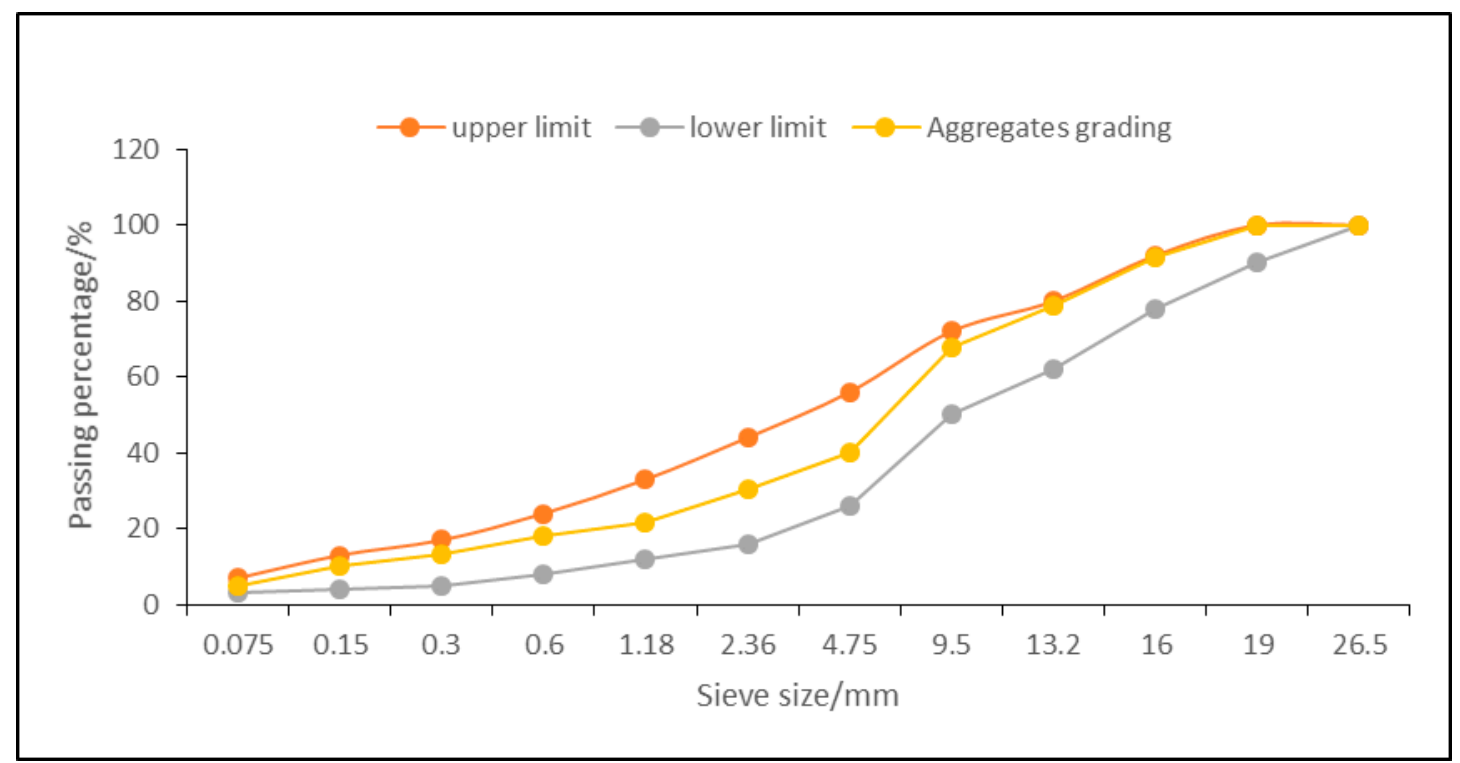

Figure 2. Gradation of the aggregates used in this study.

A plate was made according to the rutting test specifications and then cut into a suitable prism specimen.

\subsection{Test Matrix}

As shown in Figure 3, fatigue tests were performed by Material Test System (MTS) with a strain-controlled load on asphalt concrete prisms and were conducted in the laboratory.

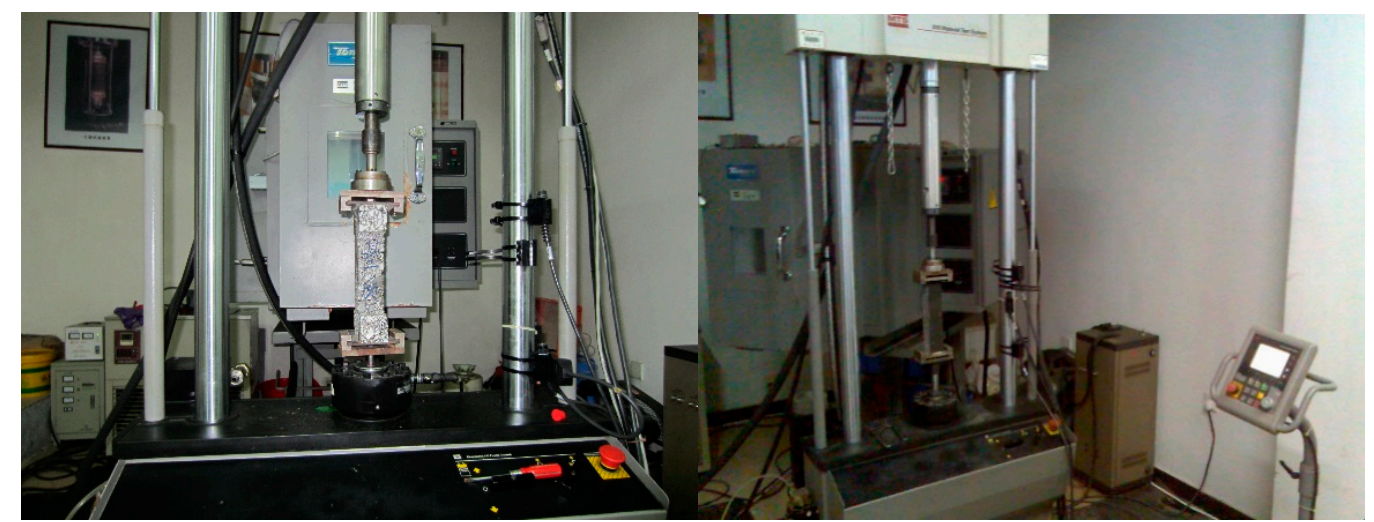

Figure 3. Material Test System (MTS).

Specimens must be a suitable shape and size for strain control and to ensure the reliability of test results. Several $300 \mathrm{~mm} \times 300 \mathrm{~mm} \times 50 \mathrm{~mm}$ plate specimens were firstly prepared and then they were cut into $250 \mathrm{~mm} \times 50 \mathrm{~mm} \times 50 \mathrm{~mm}$ prism samples in accordance with test procedures of direct tension testing in the literature [17].

As shown in Figure 4, both ends of the specimen were bonded with a steel plate, and a spherical hinge was set at the end of the active loading position, which ensured the central tension on the tip of the specimen. The strain-controlled cyclic loads were applied on a steel plate, and the spherical hinge could be automatically set back when tension was applied to the specimen. In order to avoid uncontrolled tension, the load was set on the middle of the prism. 


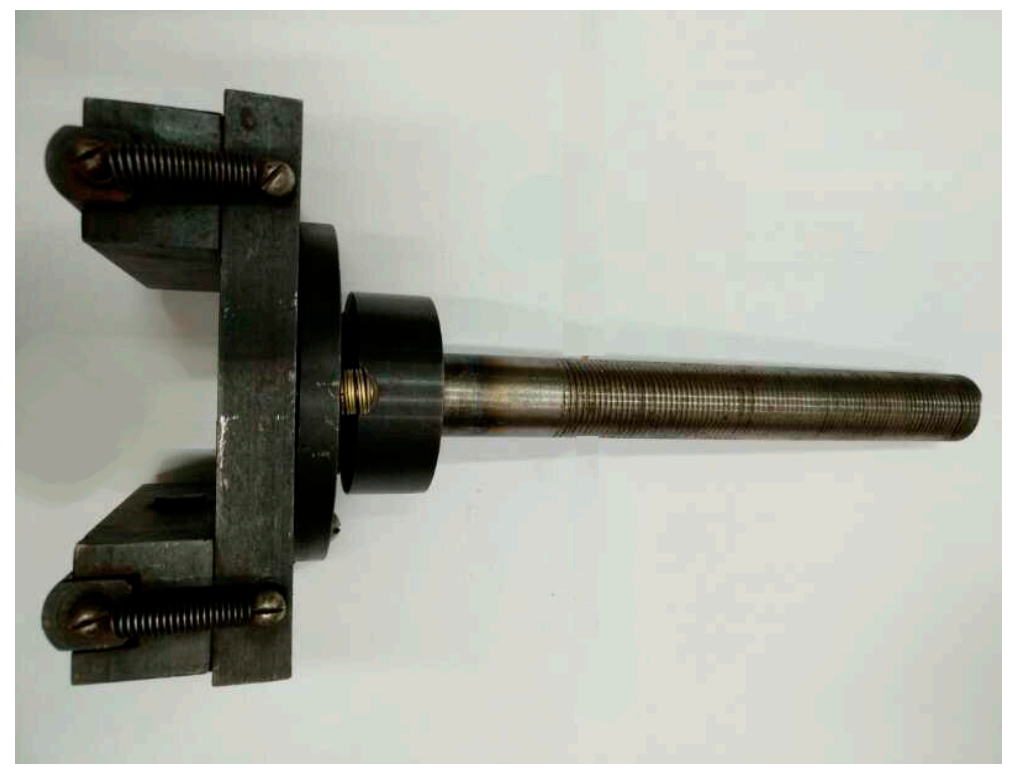

Figure 4. Specimen clamp for tests.

\subsection{Loading Frequency}

In order to make the experiment feasible and to comply with road surface conditions, the test was conducted at a variety of frequencies $(1,2,5,10 \mathrm{~Hz})$. A load frequency of $2 \mathrm{~Hz}$ was determined for the test by taking into consideration influential factors including simulation results, the test time, and fixture performance.

\subsection{Loading Waveform}

In consideration of the fixed method of the specimen clamp, a gentle tug was exerted to avoid displacing the fixture gap. A non-intermittent triangular wave for the loading waveform was adopted (see Figure 5).

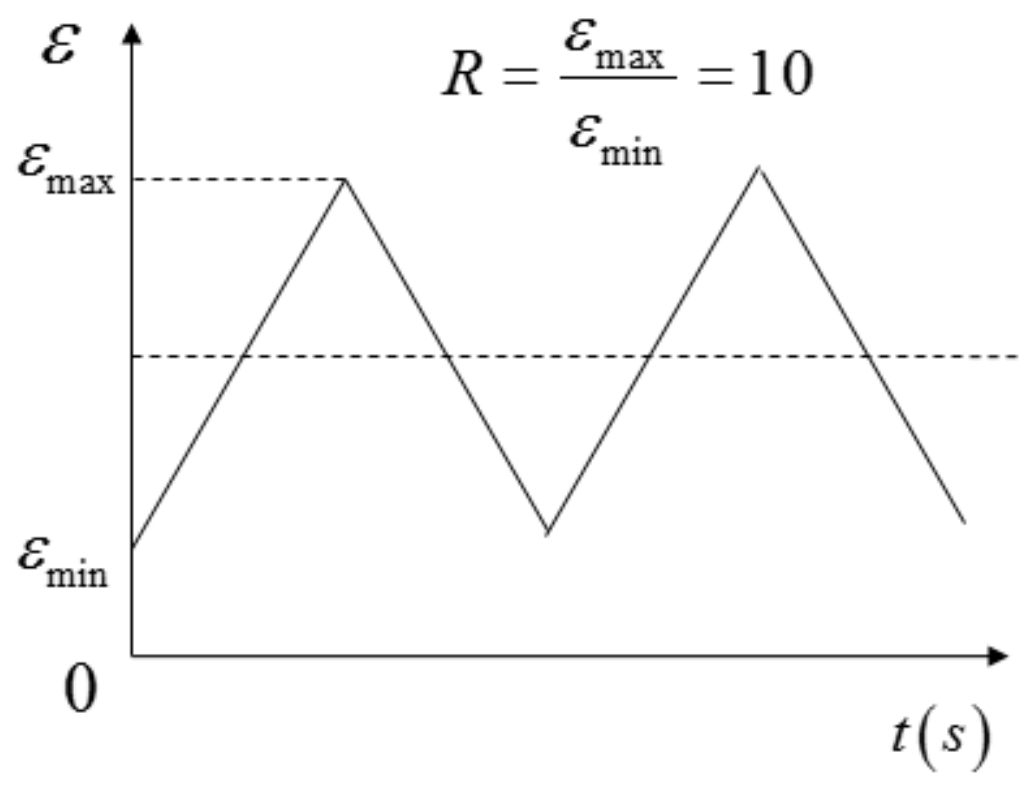

Figure 5. Loading waveform for fatigue test of High Modulus Asphalt Concretes (HMAC). 


\subsection{Test Temperature}

In order to reflect the actual working state of high modulus asphalt pavement, a fatigue equivalent temperature was calculated and used as the test temperature.

SHRP presented the method to calculate the equivalent temperature of the fatigue test $[18,19]$ :

$$
T_{\text {eff }}(F C)=0.8(M A P T)-2.7
$$

where: $T_{\text {eff }}(F C)$-equivalent temperature of the fatigue test $\left({ }^{\circ} \mathrm{C}\right) ; M A P T$-annual average surface temperature in $1 / 3$ Pavement depth $\left({ }^{\circ} \mathrm{C}\right) ; 15^{\circ} \mathrm{C}$ was determined to be the test temperature for the HMAC fatigue test.

\subsection{Failure Criteria}

Load descent failure criterion for the prism specimen was adopted after taking into consideration the asphalt mixture characteristics and test maneuverability. The specimen failed when the load decreased to $75 \%$ of the peak loading capacity $[20,21]$.

The axial strain control mode was chosen and the high-low strain ratio of the specimens was set at 10 . Four strain levels $(0.3,0.4,0.5,0.6)$ were adopted with three specimens tested in each level. Test conditions were determined, including a $2 \mathrm{~Hz}$ load frequency, a $1 \mathrm{~mm} / \mathrm{min}$ stretching rate, a $15^{\circ} \mathrm{C}$ test temperature, and a non-intermittent triangular wave for the loading waveform. These conditions were set in conjunction with the simulation effects, the test time, and clamp performance.

\section{True Cyclic Stress-Strain Curve}

The cyclic stress-strain curve, which is made by the vertices of the stable hysteresis loop at different strain levels, is a smooth curve. The following methods were used to determine the cyclic stress-strain curves:

(1) Multistage test method. Cyclic loading under several strain amplitude levels was conducted on the specimen, each cycle was loaded a number of times to achieve stability, and a smooth curve was drawn using the overlapping and stable hysteresis loop through the top. This loop was named the cyclic stress-strain curve. The method required few specimens and had a quick measurement speed; however, this method has low precision and it easily produces fatigue damage.

(2) Relegation-enhancement test method. When the specimen was loaded, the strain amplitude was gradually relegated and then enhanced. The other steps of this method are similar to the multistage test method

(3) Stretching after cycle stability method. The specimen underwent a series of strain decreases and increases, reducing the level of strain amplitude after cycle stability was reached. A specimen was then loaded to tensile failure to determine the stress-strain curve. Results of this method are in good agreement with those in the above two methods, however, it has low precision.

(4) Multistage multi-sample method. Multiple experiments controlled by a constant strain were conducted on specimens in multistage strain stages in order to obtain a stable hysteresis loop, then the top of the hysteresis loop was connected and a smooth cyclic stress-strain curve was obtained. This method can accurately reflect the cycle stress-strain properties of materials with high precision, but it requires more specimens and a longer test period than the other methods. The strength coefficient and cyclic strain hardening index are calculated using the cyclic stress-strain curve [22,23]:

$$
\frac{\Delta \varepsilon}{2}=\frac{\Delta \sigma}{2 E}+\left(\frac{\Delta \sigma}{2 K^{\prime}}\right)^{\frac{1}{n^{\prime}}}
$$

where: $\Delta \varepsilon=$ cyclic strain amplitude, $\Delta \sigma=$ cyclic stress amplitude. 
The following equation can be obtained using the plastic component calculation:

$$
\varepsilon=\frac{\sigma}{E}+\left(\frac{\sigma}{K^{\prime}}\right)^{\frac{1}{n^{\prime}}}
$$

where: $\sigma=$ stress, $\varepsilon=$ strain, $n^{\prime}=$ Cyclic strain hardening exponent, $K^{\prime}=$ Cyclic stress hardening exponent.

The strain fatigue curve shows that the values of the hysteresis loop apex were calculated when fatigue life reached $50 \%$ of the specimen at strain levels ranging from 0.3 to 0.6 in order to determine the true strain and true stress amplitude at different strain levels and the plastic strain component (see Table 2).

Table 2. True stress amplitude and plastic strain component at different strain levels.

\begin{tabular}{cccc}
\hline Strain Levels & $\Delta \varepsilon$ & $\Delta \sigma / \mathbf{M P a}$ & $\Delta \varepsilon_{p}$ \\
\hline 0.6 & 0.0014 & 0.213 & 0.00041 \\
0.5 & 0.0013 & 0.184 & 0.00038 \\
0.4 & 0.0011 & 0.176 & 0.00036 \\
0.3 & 0.00081 & 0.143 & 0.00027 \\
\hline
\end{tabular}

Table 2 shows the different fitting algorithms that were adopted to fit Equation (3). The fitting parameters $K^{\prime}=26.847$ and $n^{\prime}=0.725$ were then obtained and used in the following formula that predicts the strain of HMAC in the strain-controlled mode:

$$
\varepsilon=\frac{\sigma}{E}+\left(\frac{\sigma}{26.847}\right)^{1.3793}
$$

Stress can be obtained using Equation (4) with strains ranging from 0.0001 0.001; the results are presented in Figure 6.

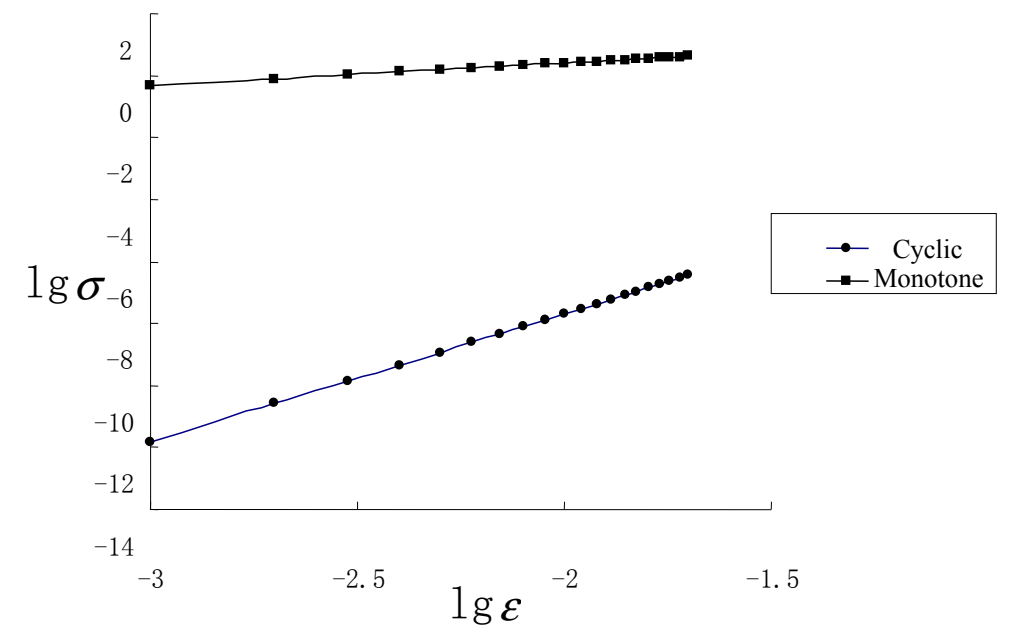

Figure 6. Comparison between cyclic curves and monotone curve.

The parameters $K, n$, and the HMAC monotone curve are compared, respectively, with the parameters $K^{\prime}, n^{\prime}$, and the cyclic curves. The cyclic curves are far higher than the monotone curve. Based on the position of the curve, HMAC was determined to be a cyclic hardening material [24], indicating that the stress required for producing the same strain during cyclic loading is higher than when under a static load. However, the hardening phenomenon gradually disappears when the cycling times increase.

Figure 7 shows the relationship between stress and time in the cyclic stress strain test with constant strain controlled. The results show that stress fluctuates as the length of time increases, whereas the 
general trend is that strain decreases along with the increasing length of time. It can be seen that the HMAC has cyclic relaxation properties [25,26], meaning strain gradually decreases when constant strain is controlled.

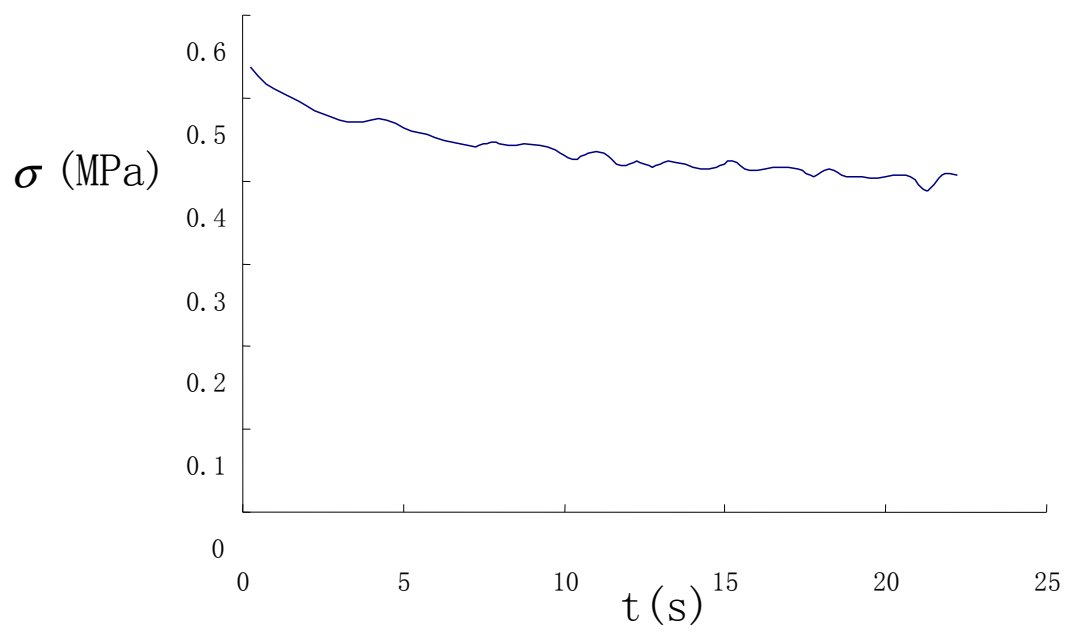

Figure 7. Stress-time history under control of strain.

\section{Determination of Local Stress and Strain}

\subsection{Neuber Equation}

The Neuber equation, a concise method for calculating local stress-strain of a notch $[27,28]$, is as follows:

$$
\begin{gathered}
K_{t}=\left(K_{\varepsilon} K_{\sigma}\right)^{\frac{1}{2}} \\
K_{\varepsilon}=\frac{\varepsilon}{e} \\
K_{\sigma}=\frac{\sigma}{s}
\end{gathered}
$$

where: $K_{t}$-theoretical stress concentration factor of notch, $K_{\varepsilon}$-strain concentration factors, $K_{\sigma}$-factor of stress concentration, $e$-nominal strain, $S$-nominal stress.

$K_{\varepsilon}$ and $K_{\sigma}$ were placed in Equation (5) and converted into an incremental form, and the Neuber hyperbolic equation was then obtained:

$$
\Delta \sigma \Delta \varepsilon=K_{t}^{2} \Delta S \Delta e
$$

If the nominal stress is in the elastic range, then $\Delta e=\frac{\Delta S}{E}$ can be obtained, and the equation is as follows:

$$
\Delta \sigma \Delta \varepsilon=\left(K_{t} \Delta S\right)^{2} / E
$$

The Neuber equation is derived from shear stress analysis of a prism. In order to be widely applied in the design and development of HMAC [29,30], the Neuber equation is modified by replacing the theoretical stress concentration factor $K_{t}$ with the fatigue notch factor $K_{f}$. The general method for determining $K_{f}$ is to fit the regression equation through fatigue test data of the specimen notch, and $K_{f}$ is typically treated as a constant for most influencing factors. $K_{t}$ is usually used when there is a lack of $K_{f}$ data, which is a conservative method for estimating fatigue life. Values of $K_{t}$ at different strain levels are shown in Table 3. 
Table 3. Theoretical stress concentration factor of notch.

\begin{tabular}{ccccc}
\hline Strain Levels & $\mathbf{0 . 6}$ & $\mathbf{0 . 5}$ & $\mathbf{0 . 4}$ & $\mathbf{0 . 3}$ \\
\hline$K_{t}$ & 1.973 & 1.947 & 2.046 & 1.938 \\
\hline
\end{tabular}

\subsection{Neuber Equation Correction}

To conform to the plane strain problem, the cycle stress-strain curve of a small smooth specimen in the uniaxial stress state test must be modified. Moreover, parameters $K_{\varepsilon}$ and $K_{\sigma}$ in the biaxial stress state are different from those in the uniaxial stress state, meaning that the Neuber equations should be modified.

\subsubsection{Cyclic $\sigma-\varepsilon$ Curve Correction}

Hooke's law was applied to the elastic strain component, whereas the plastic deformation theory was used for the plastic component:

$$
\begin{gathered}
\sigma_{a}{ }^{\prime}=\sigma_{a} /\left(1-\mu_{1}+\mu_{1}^{2}\right)^{\frac{1}{2}} \\
\varepsilon_{a}{ }^{\prime}=\varepsilon_{a}\left(1-\mu_{1}^{2}\right) /\left(1-\mu_{1}+\mu_{1}^{2}\right)^{\frac{1}{2}} \\
\mu_{1}=\frac{\mu+E \varepsilon_{p a} /\left(2 \sigma_{a}\right)}{1+E \varepsilon_{p a} / \sigma_{a}}
\end{gathered}
$$

where: $\sigma_{a}^{\prime}$-the maximum main stress under plane strain condition, $\varepsilon_{a}^{\prime}$-the maximum main strain under plane strain condition, $\mu_{1}$-generalized Poisson's ratio, $\mu_{1}=\frac{\mu+E \varepsilon_{p a} /\left(2 \sigma_{a}\right)}{1+E \varepsilon_{p a} / \sigma_{a}}, \mu$-Poisson's ratio, $\varepsilon_{p a}$-plastic strain amplitude of cyclic $\sigma-\varepsilon$ curve under uniaxial stress condition, $E_{a}$-elastic modulus of cyclic stress-strain curve.

The equation is achieved by $\sigma_{a}^{\prime}-\varepsilon^{\prime}{ }_{a}$ fitting as follows:

$$
\varepsilon_{a}^{\prime}=\sigma_{a}^{\prime}\left(1-\mu^{2}\right) / E+\left(\sigma_{a}^{\prime} / K^{\prime}\right)^{\frac{1}{n^{\prime}}}
$$

where $K^{\prime \prime}$ is corrections of $K^{\prime}, n^{\prime \prime}$ is corrections of $n^{\prime}$.

The parameter data found in Table 4 were put into Equation (13), and then the revised cyclic $\sigma-\varepsilon$ curve equation was obtained via Equation (14):

$$
\varepsilon_{a}^{\prime}=\frac{\sigma_{a}^{\prime}\left(1-\mu^{2}\right)}{E_{a}}+\left(\frac{\sigma}{590.716}\right)^{1.014}
$$

Table 4. Correction parameters of cyclic $\sigma-\varepsilon$ curve.

\begin{tabular}{cccccc}
\hline Strain Levels & $\boldsymbol{\varepsilon}^{\prime}{ }_{\boldsymbol{a}}$ & $\boldsymbol{\sigma}^{\prime}{ }_{\boldsymbol{a}} \mathbf{} \mathbf{M P a}$ & $\boldsymbol{\mu}_{\mathbf{1}}$ & $\boldsymbol{K}^{\prime \prime}$ & $\boldsymbol{n}^{\prime \prime}$ \\
\hline 0.6 & 0.682 & 0.14 & 0.427 & & \\
0.5 & 0.594 & 0.097 & 0.419 & & \\
0.4 & 0.473 & 0.083 & 0.417 & 590.716 & 0.986 \\
0.3 & 0.348 & 0.076 & 0.423 & & \\
\hline
\end{tabular}




\subsubsection{Neuber Equation Correction}

To show the plastic penetration level and equivalent stress and strain levels, the right end of the Neuber equation was multiplied by two coefficients, and the following corrections were made to the Neuber equation:

$$
\begin{gathered}
\Delta \sigma \cdot \Delta \varepsilon=m \cdot g \cdot\left(K_{f} \cdot \Delta S\right)^{2} / E \\
m=\left(1-\mu^{\prime}+\mu^{\prime 2}\right)^{\frac{1}{2}} \\
g=m /\left(1-\mu^{\prime 2}\right) \\
\mu^{\prime}=0.5-(0.5-\mu) E_{s} / E
\end{gathered}
$$

where: $m$-plastic penetrable degree, $g$-coefficient of equivalent stress and strain, $\mu^{\prime}$-elastic-plastic Poisson's ratio, considering the compressibility of material, $\mu$-Poisson's ratio, E-elasticity modulus, $E_{s}$ - secant modulus, determined by the monotone tensile curve.

Parameters $\mu^{\prime}=0.4221, m=0.87, g=1.059$ can be obtained by putting $\mu=0.25, E_{s}=374 \mathrm{MPa}$, and $E=1200 \mathrm{MPa}$ into Equation (15), which becomes the following final form of the Neuber equation that predicts the fatigue life of HMAC in the strain-controlled mode:

$$
\Delta \varepsilon \cdot \Delta \sigma=\frac{0.92\left(K_{f} \cdot \Delta S\right)^{2}}{E}
$$

As nominal stress is in the elastic range, $\Delta e=\frac{\Delta S}{E}$ and $K_{t}=1.976$ were substituted into Equations (9) and (19) to develop Equation (20):

$$
\varepsilon \sigma=0.92 \times 1.976^{2} s e
$$

\section{Strain-Life Fatigue Equation}

The strain fatigue life equation is characterized by the fatigue curve taking the following form:

(1) $\varepsilon_{a}-N_{f}$ curve.

Strain fatigue tests were conducted at different strain levels and under equal strain control to obtain the fatigue data, of the control variables $\varepsilon_{a}$ is the true strain amplitude.

(2) $\varepsilon_{e q}-N_{f}$ or $\sigma_{e q}-N_{f}$ curve.

Fatigue data are obtained from fatigue tests that combine stress and strain. The control variables are not equivalent strain amplitude $\varepsilon_{e q}$ or equivalent stress amplitude $\sigma_{e q}$, which contain the mean stress.

(3) $S-N_{f}$ curve.

The fatigue data comes from existing data from the S-N curve. The influence of notch and strain fatigue should also be considered.

The second method needs a large amount of experimental data, and the third method was only applied to make a rough estimation, because of its low accuracy. The main $\varepsilon_{a}-N_{f}$ curves are shown in Table 5. 
Table 5. Strain fatigue curve.

\begin{tabular}{|c|c|c|}
\hline Forms & Author & Expression \\
\hline$\Delta \varepsilon \sim N_{f}\left(R_{e}=-1\right)$ & $\begin{array}{l}\text { M. A. Manson } \\
\text { L. F. Coffin } \\
\text { H. M. Fu } \\
\text { R. W. Landgraf } \\
\text { Ostergren } \\
\text { K. N. Smith } \\
\text { Bergmann } \\
\text { F. Erdogan } \\
\text { V. Adrov }\end{array}$ & 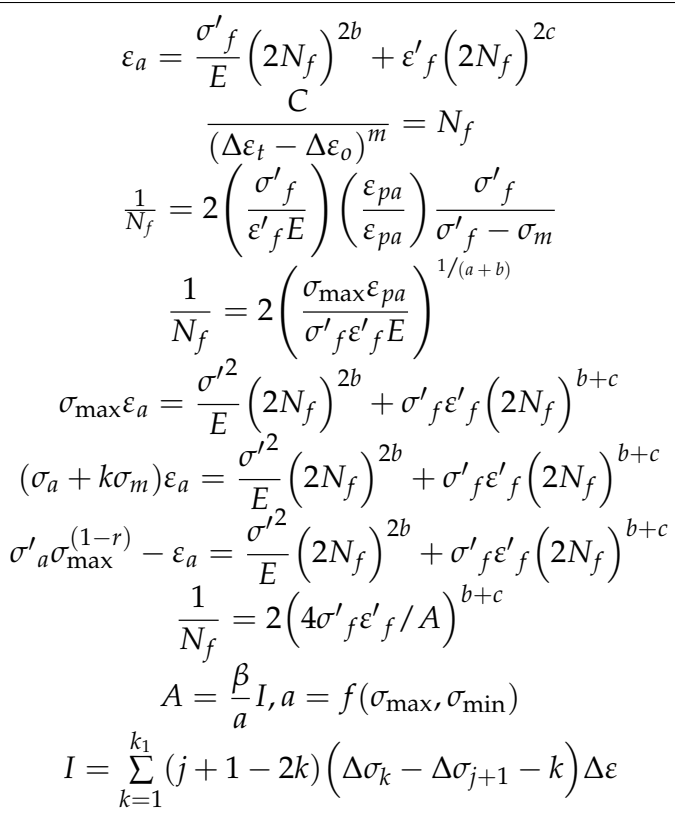 \\
\hline
\end{tabular}

The Manson-Coffin equation is widely used for all of the $\varepsilon_{a}-N_{f}$ curves by adopting a power function to characterize fatigue performance. The main parameter strain is calculated using the following equation:

$$
\varepsilon_{a}=\frac{\sigma_{f}^{\prime}}{E}\left(2 N_{f}\right)^{b}+\varepsilon_{f}^{\prime}\left(2 N_{f}\right)^{c}
$$

Based on the proposed Manson-Coffin equation, direct tensile fatigue tests for HMAC were conducted to obtain the fatigue parameters. Estimation methods for fatigue parameters included the general slope method, modified four-points correlation, and four-points correlation [31,32] (see Table 6).

Table 6. Estimation method for fatigue constant.

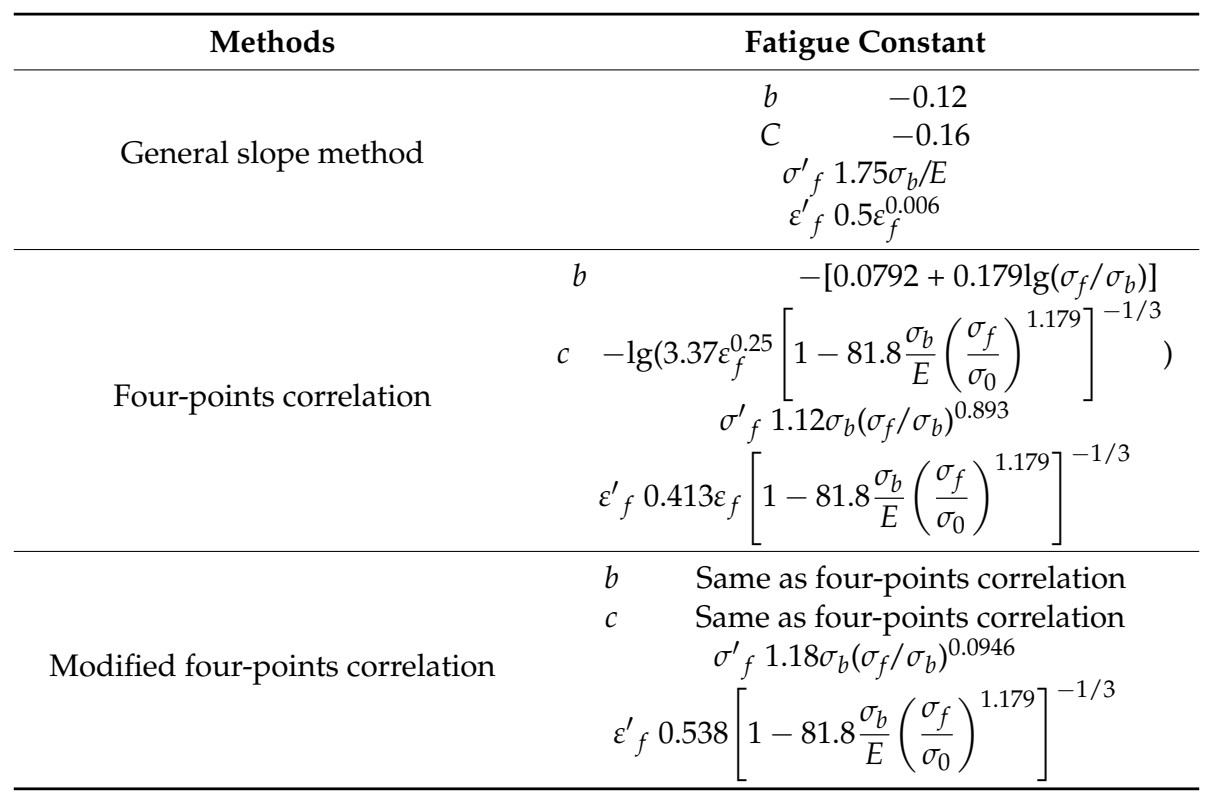


Fatigue test regulation for Manson-Coffin equation requires that $R_{e}=-1$, otherwise, the equation should be modified, (see Table 7).

Table 7. Modified Manson-Coffin equation when $R_{e} \neq-1$.

\begin{tabular}{|c|c|}
\hline Methods & Modified Manson-Coffin Equation \\
\hline $\begin{array}{l}\text { Morrow elastic stress } \\
\text { Linear correction }\end{array}$ & $\varepsilon_{\mathrm{a}}=\frac{\sigma_{f}^{\prime}-\sigma_{m}}{E}\left(2 N_{f}\right)^{b}+\varepsilon_{f}^{\prime}\left(2 N_{f}\right)^{c}$ \\
\hline Gerber elastic stress curvature correction & $\varepsilon_{\mathrm{a}}=\frac{\sigma^{\prime} \frac{2}{f}-\sigma \frac{2}{m}}{E \sigma_{f}^{\prime}}\left(2 N_{f}\right)^{b}+\varepsilon_{f}^{\prime}\left(2 N_{f}\right)^{c}$ \\
\hline Marrow total strain correction & $\varepsilon_{\mathrm{a}}=\frac{\sigma_{f}^{\prime}-\sigma_{m}}{\sigma_{f}^{\prime}} \frac{\sigma_{f}^{\prime}}{E}\left(2 N_{f}\right)^{b}+\varepsilon_{f}^{\prime}\left(2 N_{f}\right)$ \\
\hline Sachs plastic correction & $\Delta \varepsilon_{\mathrm{a}}=\frac{\sigma_{f}^{\prime}}{E}\left(1-\frac{\sigma_{m}}{\sigma_{b}}\right)^{b}\left(2 N_{f}\right)^{c}$ \\
\hline
\end{tabular}

In accordance with the first method, an equal strain fatigue test with strain levels ranging from 0.3 to 0.6 and a monotone direct tensile test were conducted on HMAC using the dynamic tester MTS810 to calculate the $\varepsilon_{a}-N_{f}$ curve of asphalt concretes [33]. The $\varepsilon_{a}-N_{f}$ curve was characterized by the Mason-Coffin equation, and the power function was adopted to describe the strain life curve:

$$
\varepsilon_{a}=\frac{\Delta \varepsilon}{2}=\frac{\Delta \varepsilon_{e}}{2}+\frac{\Delta \varepsilon_{p}}{2}=\left(\frac{\sigma_{f}^{\prime}}{E}\right)\left(2 N_{f}\right)^{b}+\varepsilon_{f}^{\prime}\left(2 N_{f}\right)^{c}
$$

In the above equations, $\sigma_{f}^{\prime}$ and $\varepsilon_{f}^{\prime}$ are approximately equal to the fracture stress $\sigma_{f}$ and fracture strain $\varepsilon_{f}$ [34]. Fracture stress and fracture strain for HMAC were listed in the monotone direct tensile test (see Table 8).

Table 8. HMAC parameters of monotone direct tensile test.

\begin{tabular}{cccc}
\hline Specimen & Fracture Strain & Fracture Stress/MPa & Secant Modulus/MPa \\
\hline SJ-1 & 0.00308 & 0.1588 & 351.55 \\
SJ-2 & 0.00384 & 0.13672 & 385.60 \\
SJ-3 & 0.0023 & 0.13465 & 413.54 \\
SJ-4 & 0.0023 & 0.10162 & 345.18 \\
Average & 0.00288 & 0.13295 & 373.97 \\
\hline
\end{tabular}

As seen in Table $8, \sigma_{f}^{\prime}$ of HMAC is $0.13295 \mathrm{MPa}$ and $\varepsilon^{\prime}{ }_{f}$ is 0.00288 . Constant strain fatigue tests at different stress-strain levels were conducted on HMAC, and the cyclic $\sigma-\varepsilon$ curve at the strain level of 0.6 is shown in Figure 8.

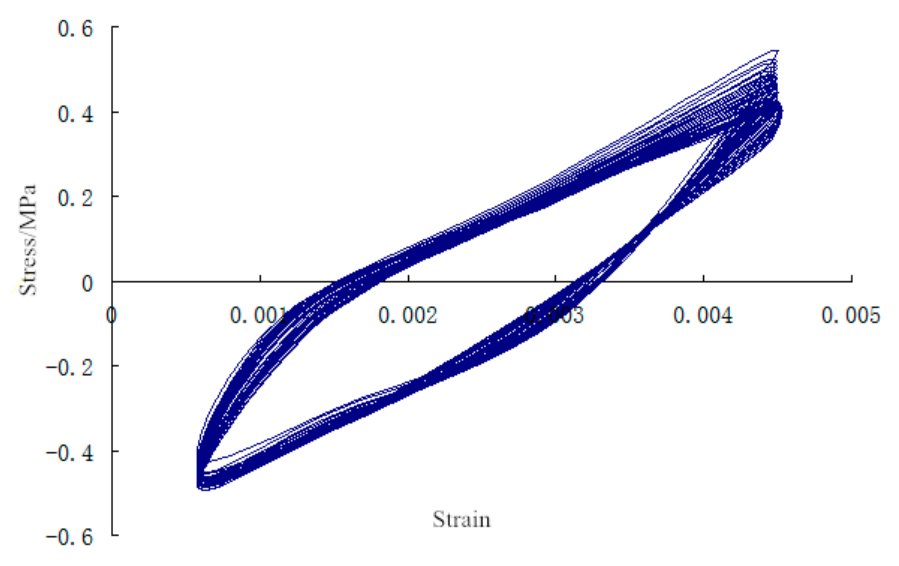

Figure 8. Cyclic $\sigma-\varepsilon$ curve at the strain level of 0.6. 
The fatigue parameters strain and fatigue life of the specimen were then obtained, as shown in Table 9.

Table 9. Strain amplitude and fatigue life of HMAC in equal strain fatigue test.

\begin{tabular}{ccccccccc}
\hline Specimen & S1 & S2 & S3 & S4 & S5 & S6 & S7 & S8 \\
\hline HMAC & & & & & & & & \\
$\varepsilon_{\mathrm{a}}$ & 0.32 & 0.53 & 0.74 & 0.91 & 1.15 & 1.392 & 1.56 & 1.66 \\
$N_{f}$ & 18242 & 15124 & 7692 & 4543 & 3692 & 2420 & 1502 & 1031 \\
\hline Matrix asphalt concretes & & & & & & & & \\
$\varepsilon_{\mathrm{a}}$ & 1.28 & 2.17 & 3.04 & 3.75 & 4.18 & 5.37 & 6.17 & 6.89 \\
$N_{f}$ & 4862 & 3941 & 1920 & 1137 & 1972 & 1143 & 108 & 84 \\
\hline
\end{tabular}

As seen in Table 9, four common fitting algorithms were used to fit the data from Equation (1). The relationship between the fitting parameters and the equation was studied, as seen in Table 10.

Table 10. Parameters $b$ and $c$ using different fitting algorithms.

\begin{tabular}{cccc}
\hline Fitting Algorithms & $\boldsymbol{b}$ & $\boldsymbol{c}$ & $\mathbf{R}^{\mathbf{2}}$ \\
\hline Marquardt method & -0.10234 & -0.10263 & 0.981687 \\
Quasi-newton method & -0.10233 & -0.10264 & 0.981688 \\
Evolution algorithm & -0.10231 & -0.10267 & 0.981681 \\
Max inherit optimization & -0.10237 & -0.10261 & 0.981687 \\
\hline
\end{tabular}

As shown in Table 10, the fitting parameters $(b, c)$ of the four fitting methods are nearly the same $-b=-0.1023$ and $c=-0.1026$. When $\sigma_{f}^{\prime}, \varepsilon^{\prime}, b$, and $c$ are put into Equation (22), then Equation (22) changes into the following form which predicts the fatigue life of HMAC in the strain-controlled mode:

$$
\varepsilon_{a}=\frac{0.13295}{E} \times\left(2 N_{f}\right)^{-0.1023}+0.00288 \times\left(2 N_{f}\right)^{-0.1026}
$$

\section{Fatigue Life Prediction Based on Local Stress-Strain Method}

The fatigue life of HMAC was predicted based on the modified Neuber equation. First, the load-time process was transformed into a nominal-time history. Second, local stress and strain of the notched specimen were transformed to nominal stress and strain using the cyclic $\sigma-\varepsilon$ curve and the modified Neuber equation. Fatigue damage was calculated according to the strain fatigue life curve, and the fatigue life was then obtained based on cumulative damage theory. Specific steps for fatigue life prediction based on the modified Neuber equation and local stress-strain method are as follows:

(1) Local strain and local stress in the plane strain state were solved using the results of the load strain and temperature strain, cyclic $\sigma-\varepsilon$ curve and Neuber hyperbolic equations.

$$
\begin{gathered}
\varepsilon=\frac{\sigma}{E}+\left(\frac{\sigma}{26.847}\right)^{1.3793} \\
\varepsilon \sigma=0.92 \times 1.976^{2} s e
\end{gathered}
$$

(2) The fatigue life $N_{f}$ was determined on the basis of the $\varepsilon_{a}-N_{f}$ curve equation.

$$
\varepsilon_{a}=\frac{0.13295}{E} \times\left(2 N_{f}\right)^{-0.1023}+0.00288 \times\left(2 N_{f}\right)^{-0.1026}
$$




\section{Case Study}

\subsection{Structure and Parameters of Pavement}

Based on the proposed fatigue life prediction method, a typical HMAC overlay pavement situated in a long steep road in Shandong province of China was selected and its fatigue life was predicted below.

The pavement structure and material parameters are listed in Table 11 . Five axle loads $(80 \mathrm{kN}$, $100 \mathrm{kN}, 120 \mathrm{kN}, 150 \mathrm{kN}$, and $180 \mathrm{kN})$ and four varied temperature range $\left(5,10,15,20^{\circ} \mathrm{C}\right)$ were considered in the analysis of nominal stress and strain. For each grade, fatigue life was calculated.

Table 11. Structure and parameters of pavement.

\begin{tabular}{ccccc}
\hline Structure Layer & Material Type & Thickness/cm & Modulus/MPa & Poisson's Ratio \\
\hline Surface & High Modulus Asphalt Concrete & 4 & 1200 & 0.25 \\
Base course & High Modulus Asphalt Concrete & 6 & 1200 & 0.25 \\
Bed course & Lean concrete & $16 \sim 28$ & $10,000 \sim 40,000$ & 0.15 \\
Subbase & Cement Stabilized Crushed Stone & 20 & 1700 & 0.2 \\
Subgrade & Graded broken stone & 16 & 250 & 0.35 \\
& Soil & & 40 & 0.35 \\
\hline
\end{tabular}

\subsection{Results}

\subsubsection{Nominal Strain}

According to the traffic axle load and varied temperature range, nominal strains at the bottom of HMAC were calculated using the finite element software, see Tables 12 and 13.

Table 12. Load strain at the bottom of HMAC.

\begin{tabular}{cccccc}
\hline Axle Load/kN & $\mathbf{8 0}$ & $\mathbf{1 0 0}$ & $\mathbf{1 2 0}$ & $\mathbf{1 5 0}$ & $\mathbf{1 8 0}$ \\
\hline Load nominal strain & 0.2319 & 0.2634 & 0.3048 & 0.3527 & 0.4156 \\
Load local strain & 0.3492 & 0.3751 & 0.4163 & 0.4806 & 0.5614 \\
\hline
\end{tabular}

Table 13. Temperature strain at the bottom of HMAC.

\begin{tabular}{ccccc}
\hline Varied Temperature Range $\left({ }^{\circ} \mathbf{C}\right)$ & $\mathbf{5}$ & $\mathbf{1 0}$ & $\mathbf{1 5}$ & $\mathbf{2 0}$ \\
\hline Temperature nominal strain & 0.1934 & 0.2486 & 0.3261 & 0.4835 \\
Temperature local strain & 0.2762 & 0.3294 & 0.4351 & 0.6214 \\
\hline
\end{tabular}

\subsubsection{Local Strain}

Based on the nominal strain shown in Tables 12 and 13, local strain was calculated using the Equations (24) and (25) (see Tables 12 and 13).

\subsubsection{The Analysis of Fatigue Damage}

Based on linear cumulative damage hypothesis, damage caused by load and the maximal varied temperature range $\left(20^{\circ} \mathrm{C}\right)$ was calculated, as shown in Table 14 . In this table, statistics of traffic loading times were collected from a traffic survey, loading times were calculated using Equation (26), and fatigue damage was the ratio of statistics of traffic loading times and calculated loading times. 
Table 14. The analysis of fatigue damage.

\begin{tabular}{cccccc}
\hline Axle Load/kN & $\mathbf{8 0}$ & $\mathbf{1 0 0}$ & $\mathbf{1 2 0}$ & $\mathbf{1 5 0}$ & $\mathbf{1 8 0}$ \\
\hline Local strain & 1.2892 & 1.4009 & 1.4432 & 1.5057 & 1.5965 \\
Calculated loading times & 79,547 & 55,698 & 15,634 & 9846 & 5765 \\
Statistics of traffic loading times & 627 & 2568 & 1931 & 122 & 70 \\
Fatigue damage & 0.0079 & 0.0461 & 0.1235 & 0.0124 & 0.0121 \\
\hline
\end{tabular}

\subsubsection{Fatigue Life Prediction}

As shown in Table 14, the cumulative fatigue damage could be calculated as 0.202 , then the pavement fatigue life which is the reciprocal of cumulative fatigue damage was calculated as 4.95, meaning the HMAC overlay might generate reflective cracking in nearly 5 years. Moreover, our in situ survey also showed that a part of the pavement surface cracked almost 4 years after overlaying. This indicates that the proposed method to predict service life of pavement agreed with practical conditions. Furthermore, the current research suggested that a stress absorbing layer should be set before HMAC overlaid between HMAC and concrete pavement.

\section{Conclusions}

This study provides an experimental investigation into the fatigue performance of high modulus asphalt concretes, including the cyclic $\sigma-\varepsilon$ test and direct tensile fatigue test. A method to predict the fatigue crack initiation life of HMAC was proposed based on the modified Neuber equation and local $\sigma-\varepsilon$ method. The following conclusions can be drawn based on this work:

(1) The cyclic $\sigma-\varepsilon$ curve and modified $\sigma-\varepsilon$ curve of HMAC in plane strain state were established.

(2) Conversion from nominal stress and strain to local strain-stress is proposed based on a modified Neuber equation and the local stress-strain method.

(3) The strain fatigue equation for HMAC is presented based on fatigue tests.

(4) The fatigue life model is able to produce satisfactory crack initiation life predictions using the local stress-strain method based on fatigue test analysis of the specimens and the modified Neuber equation.

Acknowledgments: The research was sponsored by the National Natural Science Foundation (Grant No. 51008033), the Fundamental Research Funds for the Central Universities (Grant No. 310821163502), the Transportation Department of Shandong Province (Grant No. 2008Y007), the Transportation Department of Hainan Province (Grant No. 201000005), and the Transportation Department of Hubei Province of China (Grant No. Ejiaokejiao [2013] 731).

Author Contributions: Professor Mulian Zheng was in charge of the whole research plan and paper submission matters. The first author extends gratitude to Peng Li, Jiangang Yang and Zhengliang Zhang for performing the experiment and analyzing test data, to Hongyin Li and Yangyang Qiu for offering help in doing the experiment.

Conflicts of Interest: The authors declare no conflict of interest.

\section{List of Symbols}

$\varepsilon_{a}=$ strain, $\Delta \varepsilon=$ cyclic strain amplitude, $\Delta \varepsilon_{\mathrm{e}}=$ circular elastic, $\Delta \varepsilon_{p}=$ plastic strain amplitude, $\sigma_{f}^{\prime}=$ fatigue strength coefficient, $\varepsilon_{f}^{\prime}=$ ductility coefficient, $N_{f}=$ fatigue life, $b, c=$ regression constants, $\varepsilon_{\text {ea }}=$ elastic strain, $\varepsilon_{\mathrm{pa}}=$ plastic strain, $K_{t}=$ theoretical stress concentration factor of notch, $K_{\varepsilon}=$ strain concentration factors, $K_{\sigma}=$ factor of stress concentration, $e=$ nominal strain, $S=$ nominal stress, $K_{f}=$ fatigue notch factor, $M=$ plastic penetrable degree, $g=$ coefficient of equivalent stress and strain, $\mu^{\prime}=$ elastic-plastic Poisson's ration, considering the compressibility of material, $\mu=$ Poisson's ration, $E=$ elasticity modulus, $E_{S}=$ secant modulus, determined by the monotone tensile curve. 


\section{References}

1. Forough, S.A.; Nejad, F.M.; Khodaii, A. Energy-based approach to predict thermal fatigue life of asphalt mixes using modified uniaxial test setup. J. Mater. Civ. Eng. 2016, 28. [CrossRef]

2. Zheng, M.L. Simulation of Permanent Deformation in High-Modulus Asphalt Pavement Using the Bailey-Norton Creep Law. J. Mater. Civ. Eng. 2016. [CrossRef]

3. Monismith, C.L.; Epps, J.A.; Kasianchuk, D.A.; McLean, D.B. Asphalt Mixture Behavior in Repeated Flexure; Report TE 70-5; University of California: Berkeley, CA, USA, 1971.

4. Roque, R.; Ruth, B.E.; Dickison, S.W.; Reid, B. Evaluation of SHRP Indirect Tension Tester to Mitigate Cracking in Asphalt Concrete Pavements and Overlays; Final Report FDOT B-9885; University of Florida: Gainesville, FL, USA, 1997.

5. Yoo, P.J.; Al-Qadi, I.L. A strain-controlled hot-mix asphalt fatigue model considering low and high cycles. Int. J. Pavement Eng. 2010, 11, 565-574. [CrossRef]

6. Ameri, M.; Nowbakht, S.; Molayem, M. A study on fatigue modeling of hot mix asphalt mixtures based on the viscoelastic continuum damage properties of asphalt binder. Constr. Build. Mater. 2016, 106, $243-252$. [CrossRef]

7. Li, Y.Q.; Metcalf, J.B. Crack Initiation model from asphalt slab tests. J. Mater. Civ. Eng. 2002, 14, $303-310$. [CrossRef]

8. Seung, K.J.; Seung, K.C. Development of a predictive system for estimating fatigue life of asphalt mixtures using the indirect tensile test. J. Transp. Eng. 2012, 138, 1530-1540.

9. Fallah, S.; Khodaii, A. Developing a fatigue fracture model for asphalt overlay reinforced with geogrid. Mater. Struct. 2015. [CrossRef]

10. Ker, H.W.; Lee, Y.H.; Wu, P.H. Development of fatigue cracking prediction models using long-term pavement performance database. J. Transp. Eng. 2008, 134, 477-482. [CrossRef]

11. Mohammad, S.; Kim, Y.R. Development of a Failure Criterion for Asphalt Mixtures under Different Modes of Fatigue Loading; Transportation Research Board of the National Academies: Washington, DC, USA, 2014; pp. 117-125.

12. Benedetto, H.D.; de la Roche, C.; Strom, R.L. Fatigue of bituminous mixtures. Mater. Struct. 2004, 37, $202-216$. [CrossRef]

13. Karlaftis, A.G.; Badr, A. Predicting asphalt pavement crack initiation following rehabilitation treatments. Transp. Res. C 2015, 55, 510-517. [CrossRef]

14. Molenaar, A.A.A. Structure Performance and Design of Flexible Pavements and Asphalt Concrete Overlays. Ph.D. Thesis, Delft University of Technology, Delft, The Netherlands, 1983.

15. AASHTO T 321-07. Determining the Fatigue Life of Compacted Hot Mix Asphalt (HMA) Subjected to Repeated Flexural Bending; American Association of State and Highway Transportation Officials: Washington, DC, USA, 2007.

16. Shen, S.; Carpenter, S.H. Development of an asphalt fatigue model based on energy principles. J. Assoc. Asphalt Paving Technol. 2007, 77, 525-573.

17. Graham, J.A. Fatigue Design Handbook; Society of Automotive Engineers: New York, NY, USA, 1968.

18. Edward, T.H. Performance Prediction Models in the Superpave Mix Design System; Arizona State University: Tempe, AZ, USA, 2006.

19. Kim, T.W.; Baek, J.; Lee, H.J.; Choi, J.Y. Fatigue performance evaluation of SBS modified mastic asphalt mixtures. Constr. Build. Mater. 2013, 48, 908-916. [CrossRef]

20. De Jcorreia, A.M.P.; Correia, J.A.F.O. Critical Assessment of a Local Strain-Based Fatigue Crack Growth Model Using Experimental Data Available for the P355NL1 Steel. J. Pressure Vessel Technol. 2013, 135, 011404.

21. Hu, X.; Hu, S.; Walubita, L.F.; Sun, L. Investigation of fatigue cracking: Bottom-up or top-down. In Pavement Cracking: Mechanisms, Modeling, Detection, Testing and Case Histories; CRC Press: Leiden, The Netherlands, 2008; pp. 333-344.

22. Hofko, B. Combining performance based lab tests and finite element modeling to predict life-time of bituminous bound pavements. Constr. Build. Mater. 2015, 89, 60-66. [CrossRef]

23. Castro, M.; Sanchez, J. Estimation of asphalt concrete fatigue curves-A damage theory approach. Constr. Build. Mater. 2008, 22, 1232-1238. [CrossRef] 
24. Khateeb, G.A.; Shenoy, A. A distinctive fatigue failure criterion. J. Assoc. Asphalt Paving Technol. 2004, 73, 585-622.

25. Topper, T.H.; Wetzel, R.M.; Morrow, J.D. Neubers rule applied to fatigue of notched specimens. J. Met. 1969, 4, 22-24.

26. Lee, H.J.; Lee, J.H.; Park, H.M. Performance evaluation of high modulus asphalt mixtures for long life asphalt pavements. Constr. Build. Mater. 2007, 21, 1079-1087. [CrossRef]

27. Shu, X.; Huang, B.S. Laboratory evaluation of fatigue characteristics of recycled asphalt mixture. Constr. Build. Mater. 2008, 22, 1323-1330. [CrossRef]

28. Schapery, R.A. A theory of crack initiation and growth in visco-elastic media; I: Theoretical development, II: Approximate methods of analysis, III: Analysis of continuous growth. Int. J. Fract. 1975, 11, 141-159, 369-388 and 549-562. [CrossRef]

29. Doh, Y.S.; Baek, S.H.; Kim, K.W. Estimation of relative performance of reinforced overlaid asphalt concretes against reflection cracking due to bending more fracture. J. Constr. Build. Mater. 2009, 23, 1803-1807. [CrossRef]

30. Zappalorto, M.; Lazzarin, P. Some remarks on the Neuber rule applied to a control volume surrounding sharp and blunt notch tips. Fatigue Fract. Eng. Mater. Struct 2014, 37, 349-358. [CrossRef]

31. Micaeloa, R.; Pereiraa, A.; Quaresman, L.; Cidade, M.T. Fatigue resistance of asphalt binders: Assessment of the analysis methods in strain-controlled tests. Constr. Build. Mater. 2015, 15, 703-712. [CrossRef]

32. Alireza, K.K.; Mahmoud, A. Laboratory evaluation of strain controlled fatigue criteria in hot mix asphalt. Constr. Build. Mater. 2013, 47, 1497-1502.

33. Salour, F.; Erlingsson, S. Pavement Structural Behavior during Spring Thaw; VTI Report 738 A; Swedish National Road and Transport Research Institute: Linköping, Sweden, 2012.

34. Jaeklin, E.P.; Scherer, J. Asphalt reinforcing using glass fiber grid 'Glasphalt'. In Proceedings of the 3rd International RILEM Conference on Reflective Cracking in Pavement: design and performance of overlay systems, Maastricht, The Netherlands, 2-4 October 1996.

(C) 2017 by the authors. Licensee MDPI, Basel, Switzerland. This article is an open access article distributed under the terms and conditions of the Creative Commons Attribution (CC BY) license (http:/ / creativecommons.org/licenses/by/4.0/). 